\title{
Barbara-Petchenik-Wettbewerb 2017
}

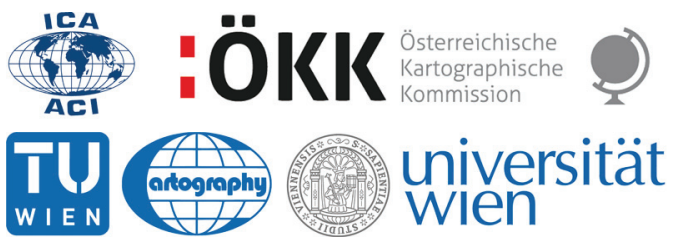

Der Barbara Petchenik Preis wurde 1993 von Internationalen Kartographischen Vereinigung (ICA) gestiftet. Der Wettbewerb ist nach der früheren Vizepräsidentin der ICA Barbara Petchenik benannt, deren kartographisches Schaffen vor allem Karten für Kinder gewidmet war. Ziel ist es, die graphische Repräsentation der Welt durch Kinderhand zu fördern.

Die Preise werden alle zwei Jahre im Rahmen der Internationalen Kartographischen Konferenz verliehen. Das Thema der aktuellen Ausschreibung ist "We love maps". Es soll eine möglichst farbige Karte der gesamten Welt oder einem großen Teil davon auf Papier mit Buntstiften, Wasserfarben, etc. gezeichnet oder aus anderem Material, wie farbigem Papier, Plastik, Karton u.dgl. hergestellt werden. Die Teilnahme am Wettbewerb ist auf Schüler/innen unter 16 Jahre beschränkt, die entweder alleine oder in Gruppen von maximal drei Autorinnen und Autoren derselben Altersgruppe arbeiten können. Die Prämierung erfolgt in vier Altersgruppen:

- unter 6 Jahre

- 6 bis 8 Jahre

- 9 bis 12 Jahre

- 13 bis 15 Jahre

Eine nationale Jury wird die eingesandten Karten begutachten und die besten Beiträge pro Altersgruppe prämieren. Bewertet wird u.a., ob die Karte eine dem Anliegen des Wettbewerbes und eine dem selbst gewählten Titel entsprechende Aussage enthält. Zudem werden der kartographische Inhalt und dessen Qualität unter Berücksichtigung der Altersgruppe evaluiert. Alle Teilnehmer/innen bekommen eine Urkunde. Darüber hinaus erhalten die Gewinner/innen ein kartographisches Geschenk.

Die sechs besten nationalen Einsendungen werden

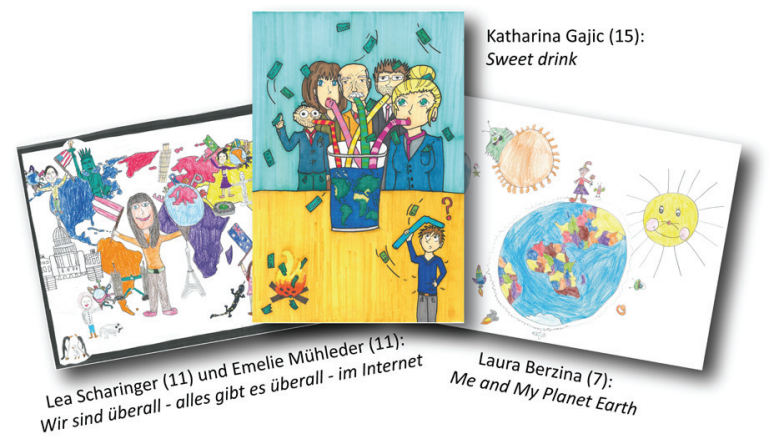
zum internationalen Wettbewerb im Rahmen der 28. Internationalen Kartographischen Konferenz in Washington DC, USA vom 2. bis 7. Juli 2017 eingereicht. Dort begutachtet eine internationale Jury die ausgestellten Karten und prämiert in der Abschlusssitzung der Konferenz die besten drei Karten pro Altersgruppe. Des Weiteren werden ein Publikumspreis sowie eine Kreativitätsauszeichnung verliehen.

Die eingesandten Karten werden in der Carleton Universitätsbibliothek in Ottawa, Kanada aufbewahrt und sind auf der Universitätswebseite (http://children.library.carleton.ca) präsentiert. Die prämierten Karten werden außerdem internationalen Organisationen, wie dem UNICEF Kinderhilfswerk der Vereinten Nationen zur Verfügung gestellt, um Postkarten, Poster, Bücher, CD-ROMs u.dgl. zu erstellen. Des Weiteren können die Karten nach dem Wettbewerb nicht zurückgegeben werden, da diese bei Veranstaltungen der Österreichischen Kartographischen Kommission und anderen Symposien ausgestellt werden.

Das notwendige Zustimmungsformular sowie detaillierte Angaben zur Erstellung der Karten finden Sie auf unserer Website: http://cartography.tuwien.ac.at/bpetchenik

Noch bis 3. Februar 2017 können Karten an den nationalen Koordinator des Wettbewerbs geschickt werden.

Gilbert Kotzbek BSc MSc

Institut für Geographie und Regionalforschung

Arbeitsgruppe Kartographie und Geoinformation

Universitätsstraße 7 (NIG)

A-1010 Wien 